\title{
How market-oriented education policies might influence young people's health: development of a logic model from qualitative case studies in English secondary schools
}

\author{
Chris Bonell, ${ }^{1}$ Adam Fletcher, ${ }^{1}$ Annik Sorhaindo, ${ }^{2}$ Helene Wells, ${ }^{1}$ Martin McKee ${ }^{1}$
}

${ }^{1}$ Faculty of Public Health and Policy, London School of Hygiene and Tropical Medicine, London, UK

${ }^{2}$ Population Council, Colonia Del Carmen Coyoacán, México, D.F, México

\section{Correspondence to} Chris Bonell, Faculty of Public Health and Policy, London School of Hygiene and Tropical Medicine, 15-17 Tavistock Place, London WC1H 9SH, UK chris.bonell@lshtm.ac.uk

Accepted 27 May 2011 Published Online First 28 June 2011

\section{ABSTRACT}

Background School systems are increasingly typified by diversity of provision, parental choice and publication of performance data. Schools shape their students' lifestyles and health, but the effects of 'marketisation' are under-researched. The authors use qualitative data to develop a logic model regarding such effects.

Methods Case studies in seven English secondary schools, interviews with 103 students and 39 staff. Results 'Parental choice' was associated with dispersal of students' friendship groups on transition to secondary school, reduced social support and emotional harms. 'Choice' meant some schools were regarded as 'dumping grounds' for socially disadvantaged students, creating potentially violent environments where students engaged in risk behaviours such as substance use to facilitate protective bonds with peers. Schools focused strongly on academic attainment, reflecting external pressures from the school inspectorate and performance league tables. Some schools sought to improve their league table position by targeting resources on 'key marginal' students on the threshold of passing five exams, the key metric. Less-academic students commonly became disengaged, engaging in various health risk behaviours as alternative status markers. The exam-focused environment aroused anxiety among high and low attainers, some using substances as self-medication. Schools also de-prioritised health education and sport in this performance-driven context.

Conclusion Our logic model aims to guide further research on how marketisation might affect young people health behaviours.

\section{INTRODUCTION}

Internationally, market-orientated reforms of schooling systems have introduced diversity of provision with schools exercising control over admissions and budgets, parental choice and publication of performance data based on student attainment, for example, as local league tables. ${ }^{12}$ In England, the process is accelerating as coalitiongovernment policies extend such reforms. ${ }^{3}$ Parents can now set up their own 'Free Schools', similar to US 'Charter Schools', which determine their own admission policies and receive funding directly from central government.

Research reveals that semi-independent Charter Schools perform no better than mainstream schools ${ }^{45}$ but increase segregation. ${ }^{67}$ Schools' 'game' test systems to enhance their performance ${ }^{8}$ and inequalities in admissions and attainment remain. ${ }^{1}$
How schools are run and how they support and engage students influences health outcomes ${ }^{9}$ yet the potential health effects of education reforms remain unexamined. We use qualitative research to generate a preliminary logic model for these. Logic models are increasingly used to theorise and test the effects of interventions on health and other outcomes. ${ }^{10}$ We ask how do staff and students refer to market-oriented policies in their accounts of school organisation and how does this organisational context relate to their accounts of health-related outcomes?

\section{METHODS}

We use qualitative data from three previous studies of seven English secondary schools ${ }^{11} 12$ involving 103 students (age 11-15) and 39 staff. We used a case study approach to understand social processes in context. ${ }^{13}$ Three schools were rated 'satisfactory', two 'good' and two 'outstanding' (in England, a national school inspectorate rate all schools as unsatisfactory, satisfactory, good or outstanding based on a short visit). Schools varied by student entitlement to free school meals $(7 \%-55 \%)$ and proportion attaining five grades $\mathrm{A}^{*}$ (ie, $\mathrm{A}+$ ) to $\mathrm{C}$ in their General Certificates of Secondary Education (GCSEs) (the public exams taken at age 16, 32\%$76 \%$ ). Purposive sampling ensured variations in students' gender, ethnicity and engagement (data available on request). Interviews occurred in private, on-site, lasting 30-90 min, were audio-recorded and transcribed. Each study was approved by the school's management team and the London School of Hygiene and Tropical Medicine's research ethics committee and sought informed consent for participation (with parents entitled to refuse children's participation).

Drawing on grounded theory, thematic content analysis of these data was undertaken to identify recurrent themes and patterns, initially through open/in vivo coding based on the respondents' own words. Further analyses focused on more closed/ detailed coding of these emerging themes and patterns. Deviant cases were examined to test and refine the emerging analysis. Quotes were selected to illustrate themes. All names used below are pseudonyms.

\section{RESULTS}

Uncertain transitions, 'dumping grounds' and 'safe' identities

Uncertainty and fear regarding the primary-tosecondary school transition at age 11 were major 
themes in students' accounts. Friendship groups were often dispersed, and feelings of anxiety and the urgent need to gain social support through new friendships were frequently cited (table 1, quotes 1 ).

Within the local 'market', 'Park Grove' and 'Hillside' were repeatedly characterised by students and staff as popular secondary schools where applications exceeded places, whereas 'Highbridge', 'Elmhurst' and 'North Street' were perceived as unpopular 'dumping grounds' (quote 2). Students and teachers in these schools reported that their schools' intake was skewed towards more socially disadvantaged students and were described as violent intimidating places (quotes 3). Some students responded by developing self-protective 'safe' identities (this term was colloquially used by students meaning 'cool' but also secure) and bonding with similarly identified students. These 'safe' identities were paradoxically based on engaging in risk behaviours, such as drug use (quotes 4). Teachers reported that a culture of gang involvement, violence and drug use could become endemic, with students finding it difficult to balance 'safe' identities with learning (quotes 5).

These accounts suggest two pathways via which adverse health effects may occur due to increasing school 'choice': through the loss of social support on transition to secondary schools and where children from low-income families are segregated in intimidating environments. Health risks and inequalities may be engendered by students engaging in risk behaviours to develop protective friendships and stay safe in such schools.

\section{The 'A-C economy': generating disengagement and anxiety}

The most prominent theme in teachers' accounts of why schools focus so much on attainment was the publication of school performance league tables. The key metric was the proportion of students achieving five GCSEs grades $A^{*}-C$ (quote 6). 'Woodbridge' and Park Grove staff reported that this focus had prompted the school to target extra support and rewards to a few students predicted to be on the 'borderline' of achieving this. This targeting of what staff termed 'key marginal' students was seen as an opportunity to increase the school's league table position (quote 7).

This strategy was acknowledged as discriminating against and disengaging students with lower predicted attainment (quote 8). Although students did not refer to the 'A-C economy', their accounts suggested pathways via which neglect of, and failure to engage, less-academic students could shape various health risk behaviours: such students saw no reason to avoid risk behaviours and/or saw behaviours such as smoking or drug use as alternative markers of social and group identity (quote 9).

Some students reported how the focus on attainment caused them anxiety, including high attainers worried about not

Table 1 Quotes from research participants

\section{No. Quote}

1 When I first started, I was really scared because I only knew one person in my class who was at my primary school. [Female, year-7, 'Woodbridge']

It's scary [in year-7]. You've gotta stand up for yourself, make your name, make friends. [Male, year-10, 'Highbridge']

2 We are seen as probably the worst school in the local area... It's just parental expectation, they look at the exam tables in papers and think, oh, 'Riverside' 85 per cent [getting good grades in five subjects in public exams], that's where my child's going. So we often get left as the dumping-ground and we do have problems. [Teacher, 'Elmhurst']

3 There are elements to it that can be quite rough and frightening, especially I think if you are a small child in year-7 [age 11-12] ... I don't think it's an easy school to come to... it's an inner-city school, you have some rough days. [Teacher, 'Highbridge']

It's not like American schools [on TV], it's not like Hannah Montana stuff [laughing]—-there's real danger!. [Female, year-10, North Street]

4 That's why you smoke [cannabis]... you wanna look bad. People think you're a bad boy or bad girl. With me they are cool and I'm safe with the boys here. [Female, year-10, Highbridge]

You have to pretend to be naughty. You have to be naughty to get on with all the naughty kids. [Female, year-7, 'Elmhurst']

5 You can't be yourself, you follow the group... Some groups are so heavily involved in and identified by things like drugs that it would be harder to step back from those things. [Teacher, 'Highbridge']

This lad... he's known as one of the cool gang, he came up to me and he asked 'Are you sure, I'm meant to be [in the higher academic stream] sir... I should be a little bit lower,'... It's just about losing face, and we have quite a few students that have that, kind of, attitude really, they're more about their appearance or what happens outside of school. And the gang, kind of, culture really, 'cause there's quite a few little gangs around the school. [Teacher, 'Woodbridge']

6 Well, I think basically we're here to bring about school improvement in terms of arithmetic targets... to get the school at $94 \%$ GCSE A $^{*}-\mathrm{C}$ grades... We've always been target driven. [Head-teacher, 'Hillside']

7 It's looking at about how they develop what they're doing, where they are, predicted grades, aspirational grades .... the key-marginals - kids who, actually, if we put some time and attention in... we get the grades up, and actually, the whole school grades would go up. [Head-teacher, 'Woodbridge']

8 That's where it is: C/D borderline. So: your As are okay; your Bs are okay; C/D, you're being focused on. What happens to the rest of you? And I think it's made them probably feel even more pushed out. [Teacher, 'Woodbridge']

9 You just [get 'stoned'] 'cos there's no reason not to!. [Male, year-10, 'Highbridge'] There's all different kinds of groups [at this school]. Quiet people, loud people, and then blazers [cannabis users] like me!. [Female, year-10, 'Park Grove']

10 Yeah, I'd say that 'cause I'm in an express group, like, the highest group... they think, 'Oh, you're a top class, you should be getting this' like, sixes in my maths and, yeah... it makes me feel nervous, 'cause if I don't, I might, like, disappoint them, and they might not think as much of me. [Male, year-7, Southborough]

11 Like you're having a bad day then just have a spliff in the morning then it's a good day. Pressure and stress can make people take drugs. If people don't like the environment they're in they are not going to be comfortable and getting on at school. [Female, year-10, Park Grove]

One girl [in Year 10] was caught recently sniffing solvents by her parents at home and she was the last person you would expect... It was pressure, pure and simple. She had a lot of expectations on her, from herself, her parents, the school and she had to find somewhere to escape it. She obviously couldn't raise it with anyone else so she dealt with it herself by getting high. [Teacher, Highbridge]

12 Ultimately it is all about achievement. That is obviously what the school is about. It's at the heart of our work. Everything else is to do with achievement. So, we might work on uniform, attendance and punctuality but the ultimate goal is for higher achievement. [Assistant head-teacher, 'Park Grove']

13 Just like, for example, national curriculum [physical education], the government try to make it, I don't know, more academic really, and I think in terms of healthy students and exercise for students we lost a lot. [Teacher, 'Woodbridge']

14 It will be a one-day inspection. Read into that what you will about how much of a priority drugs education guidelines are likely to be in reality! How can inspectors ever know about the quality of drugs education or whether we do what the policy says over the last four years from a one-day visit? No-one is measuring it!. [Teacher, 'Park Grove'] The whole [national school inspectorate] agenda now is all about standards of achievement; that's more important than anything else... things like the 'Eco-Schools', 'Investors in People', 'Healthy Schools Awards', all of these sorts of things, if your [academic] standards don't come up to scratch, you know, forget all of that. You might as well not be bothering doing it!. [Head-teacher, 'Elmhurst'] 
Figure 1 Logic model of mechanisms by which market-oriented education policies might influence students health.

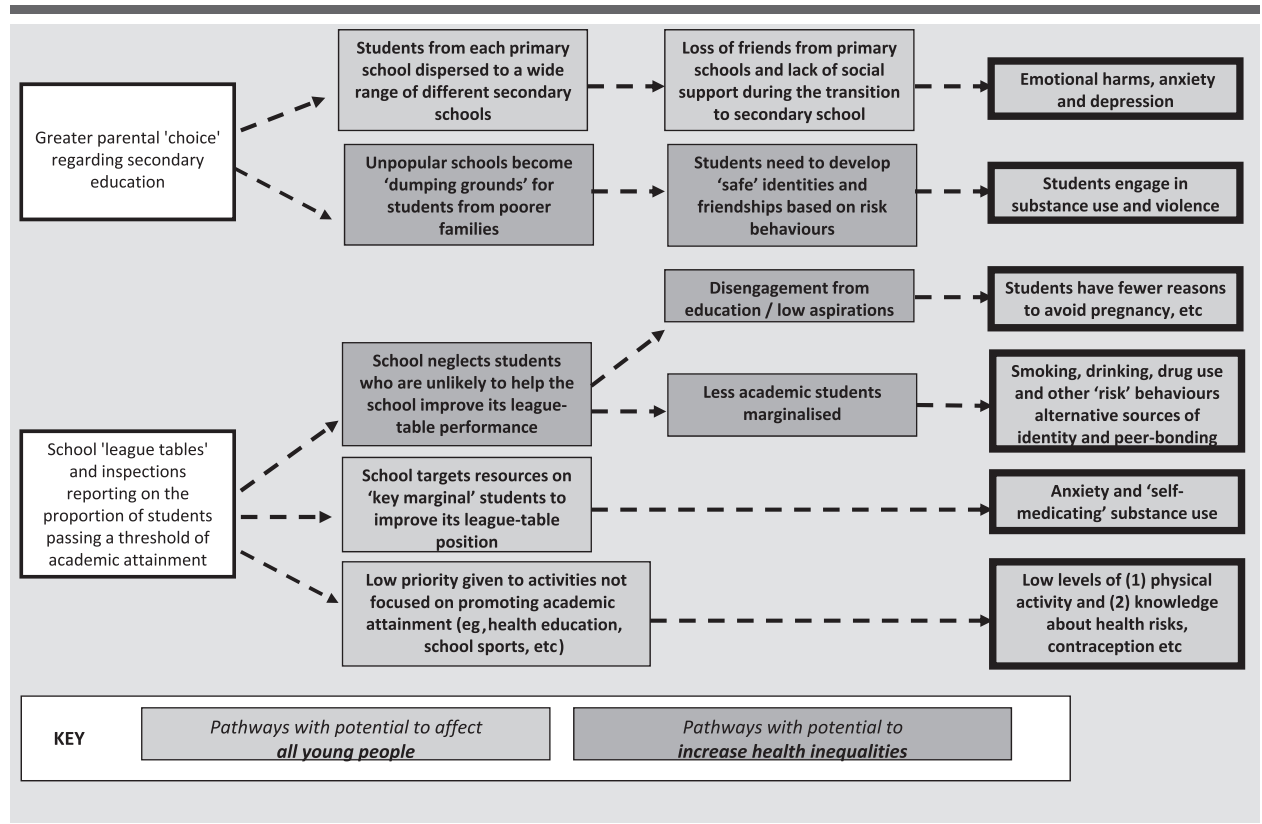

meeting expectations (quote 10). Anxiety could encourage students to use various substances as 'self-medication' (quotes 11). Thus, the A-C economy in schools might contribute to emotional harms and increased risk behaviours among those on whom it focuses most attention as well as students it marginalises.

\section{The attainment agenda and the neglect of health education and sport}

The focus on attainment was prominent in all participants' accounts (quote 12). Staff implicated this focus in the declining attention given to activities such as school sports (quote 13). The national school inspectorate's emphasis on examination results was also cited in schools' choosing to place less emphasis on health education and pastoral care (quote 14).

\section{DISCUSSION}

Our sample is large for a qualitative study but, as with most social research, generalisability is uncertain. Although we addressed multiple aspects of school life and health outcomes, we cannot offer in-depth analyses of these. Nonetheless, our data suggest that various health risks may be shaped by common processes. Qualitative data allow us to generate new insights into the pathways by which schools might have pathogenic effects, but we cannot definitively test for such effects.

In figure 1, we set out a preliminary logic model for how market-oriented education policies might influence health and health inequalities. Parental choice may cause emotional harms via increasing dispersal of friendship groups and encourage violence, substance use and other risk behaviours in dumping ground schools. League tables may encourage neglect of low attainers some of whom make complex but rational decisions in constrained circumstances to 'disinvest' in education and see little reason to postpone pregnancy ${ }^{14}$ and may use substances as alternative 'markers' of identity. This pressurised environment can also cause anxiety among low and high attainers, some of whom use substances as self-medication. Finally, pressures on schools to maximise attainment may lead schools to neglect health education and sport.

In testing out our logic model in relation to existing research, we acknowledge that the public health literature has to date largely viewed schools as benevolent institutions, engagement with which confers health benefits, ${ }^{15}{ }^{16}$ but there is evidence that school transitions can arouse stress with long-term consequences $^{17}$ so that policies rendering these more stressful may harm health. Research suggests that marketised systems increase inequalities in school admissions ${ }^{18}$ and that health behaviours are influenced by school friendship networks, ${ }^{19}{ }^{20}$ supporting our suggestion that marketisation may harm the health of students in dumping ground schools via peer effects. Our suggestion that policies that increase school disengagement will also cause health harms is supported by studies demonstrating the health benefits of connection with school. ${ }^{15}$

Further research is required to refine and test our model. This should explore whether our findings apply elsewhere and quantitatively test hypotheses derived from our logic model. We will aim to do this in our own ongoing synthesis of quantitative and qualitative research on school effects on health. Evaluations might examine the health effects of attempts to mitigate some of the harms suggested here. These include random lots to facilitate social-mixing between schools, ${ }^{21}$ which may reduce harms arising from some schools becoming dumping grounds, and re-orientation of league tables to focus median attainment and measures of 'spread' (ie, inequality), rather than proportions achieving a certain threshold. Finally, alternative approaches may be needed for students who cannot fit into current models. American research suggests that while schools can reduce violence among adolescents expecting to graduate from college, the school's performance and culture have no impact on disengaged groups whose expectations are entrenched. ${ }^{22}$ However,

\section{What is already known on this subject}

Schools in the UK and elsewhere are increasingly subject to quasi-markets typified by diversity of provision, with parental choice informed by publication of school performance data. Educational research suggests that these reforms may increase social inequalities in admissions and may not improve attainment but health effects remain unexplored. 


\section{What this study adds}

- Greater parental choice may, first, cause emotional harms, anxiety and depression via increasing dispersal of primary school friendship groups and, second, produces dumping ground schools where socially disadvantaged young people adopt violence, substance use and other risk behaviours in order to develop a 'cool'/'safe' identity and protective bonds with peers.

- League tables based on school performance may encourage neglect of low-attaining students who, once disengaged, see little reason to postpone pregnancy or not to embrace smoking, drinking or drug use as alternative 'markers' of selfand group identity. This pressurised environment can also cause anxiety among all students as well as the neglect of basic health promotion activities.

- We recommend further research to refine our logic model including evaluations of several suggested initiatives to ameliorate the impacts identified.

there are some signs of hope. 'Studio Schools' which focus on enterprise, practice-based learning and coaching are one approach. $^{23}$

Funding This work was supported by two grants from the Medical Research Council (G0601637 and G0701735) and a studentship award from the Medical Research Council (no grant code). The researchers were independent of the funders who played no role in study design, data collection and analysis, interpretation or write-up.

Competing interests None declare.

Ethics approval This study was conducted with the approval of the London School of Hygiene and Tropical Medicine.

Contributors $\mathrm{CB}$ conceived this paper, directed each research project and drafted this paper. CB had full access to all the data in the study and takes responsibility for the integrity of the data and the accuracy of the data analysis. AF codirected two of the research projects, collecting and analysing data, and contributing to drafting this paper. AS was study manager on one project, contributing to data collection and analysis and contributed to drafting this paper. HW and MM contributed to drafting this paper. All authors had full access to all of the data in the study and can take responsibility for the integrity of the data and the accuracy of the data analysis.

Provenance and peer review Not commissioned; externally peer reviewed.

\section{REFERENCES}

1. Ball SJ. The Education Debate: Policy and Politics in the 21st Century. Bristol: Policy Press, 2008.

2. Herbst J. School Choice and School Governance: A Historical Study of the United States and Germany. New York: Palgrave Macmillan, 2006.

3. Department for Education. The Importance of Teaching. The Schools White Paper 2010. London: Stationery Office, 2010.

4. Bettinger EP. The effect of charter schools on charter students and public schools. Econ Educ Rev 2005;24:133-47.

5. Bifulco R, Ladd HF. The impacts of charter schools on student achievement: evidence from North Carolina. Education, Finance and Policy 2006;1:50-90.

6. Renzulli LA, Roscigno J. Charter schools and the public good. Contexts 2007:6:31-6.

7. Weiher GR, Tedin KL. Does choice lead to racially distinctive schools? Charter schools and household preferences. J Policy Anal Manage 2002;21:79-92.

8. Haney W. Evidence on Education under NCLB land How Florida Boosted NAEP Scores and Reduced the Race Gap). Boston MA: Center for the Study of Testing, Evaluation and Education Policy. Lynch School of Education. Boston College, 2006.

9. West P, Sweeting H, Leyland A. School effects on pupils' health behaviours: evidence in support of the health promoting school. Res Paper Educ 2004;19:261-91.

10. McLaughlin JA, Jordan GB. Logic models: a tool for telling your program's performance story. Eval Program Plann 1999;22:65-72.

11. Fletcher A, Bonell C, Sorhaindo A, et al. How might schools influence young people's drug use? Development of theory from qualitative case-study research. $J$ Adolesc Health 2009:45:126-32.

12. Bonell C, Sorhaindo A, Allen E, et al. School-ethos interventions to reduce substance use: possible pathways of impact suggested by a pilot trial. $J$ Adolesc Health 2010;47:555-63

13. Yin R. Case Study Research: Design and Methods. London: Sage, 1994.

14. Arai L. Tenage Pregnancy: The Making and Unmaking of a Problem. Bristol: Policy Press, 2009.

15. Catalano RF, Haggerty KP, Oesterle $S$, et al. The importance of bonding to school for healthy development: findings from the Social Development Research Group. J Sch Health 2004; 74:252-61.

16. McNeely C, Falci C. School connectedness and the transition into and out of healthrisk behavior among adolescents: a comparison of social belonging and teacher support. J Sch Health 2004;74:284-92.

17. West P, Sweeting H, Young R. Transition matters: pupils' experiences of the primary-secondary school transition in the West of Scotland and consequences for well-being and attainment. Res Paper Educ 2010;25:21-50.

18. Ball S. Class Strategies and the Education Market: the Middle Classes and Social Advantage. London: Routledge Falmer, 2003.

19. Ennett ST, Bauman KE, Hussong A, et al. The peer context of adolescent substance use: findings from social network analysis. J Res Adolesc 2006;16:159-86.

20. Fletcher A, Bonell C, Sorhaindo A. You are what your friends eat: systematic review of social network analyses of young people's eating behaviours and bodyweight. $J$ Epidemiol Community Health 2011;65:548-55.

21. New Secondary Admissions System Agreed. http://www.brighton-hove.gov.uk/ index.cfm?request $=c 1144627$ (accessed 22 Feb 2011).

22. Birnbaum AS, Lytle LA, Hannan PJ, et al. School functioning and violent behavior among young adolescents: a contextual analysis. Health Educ Res 2003; 18:389-403.

23. Young Foundation. Studio Schools: Real Work, Transferable Skills, Aspirational Learning. London: Young Foundation, 2007 